\title{
Modeling and Analysis of Unbalanced Magnetic Pull in Synchronous Motorized Spindle Considering Magneto-thermal Coupling
}

wei feng

Henan University of Technology

Kun Zhang

Henan University of Technology

Zongyao Liu

Henan University of Technology

Baoguo Liu ( $\sim$ bgliu1978@sina.com )

Henan University of Technology

Huijuan Zhang

Henan University of Technology

Junwei Mei

Henan University of Technology

Luji Wu

Zheng Zhou Research Institute of Mechanical Engineering CO., LTD

\section{Research Article}

Keywords: Unbalanced magnetic pull, synchronous motorized spindle, magneto-thermal coupling, air gap length, thermal deformation

Posted Date: November 2nd, 2021

DOI: https://doi.org/10.21203/rs.3.rs-970121/v2

License: (c) (1) This work is licensed under a Creative Commons Attribution 4.0 International License.

Read Full License 


\section{Modeling and Analysis of Unbalanced Magnetic Pull in Synchronous Motorized Spindle Considering Magneto-thermal Coupling}

Wei Feng ${ }^{1,2}$, Kun Zhang ${ }^{2}$, Zongyao Liu ${ }^{2}$, Baoguo Liu ${ }^{1,2^{*}}$, Huijuan Zhang ${ }^{3}$, Junwei Mei ${ }^{2}$,Luji Wu ${ }^{4}$

${ }^{1}$ Henan Key Laboratory of Super Hard Abrasives and Grinding Equipment, Henan University of Technology, Zhengzhou, 45001, China

${ }^{2}$ School of Electromechanical Engineering, Henan University of Technology, Zhengzhou 450001, China

${ }^{3}$ School of Electrical Engineering, Henan University of Technology, Zhengzhou 450001, China

${ }^{4}$ Zheng Zhou Research Institute of Mechanical Engineering CO., LTD, Zhengzhou 450001, China *E-mail: bgliu1978@sina.com

\section{Abstract:}

The unbalanced magnetic pull (UMP) is one of the main vibration sources of the motorized spindle. A calculation model of UMP in a synchronous motorized spindle considering the magneto-thermal coupling is proposed in this paper. The finite element analysis models of the electromagnetic field and the temperature field of a motorized spindle are first established. Then a two-way coupling analysis method considering the effect of temperature variations on electromagnetic material properties of the motor is proposed. An experiment is conducted to verify the efficiency of this method. The thermal deformations of the spindle are calculated and used to analyze the air-gap variations between rotor and stator of the built-in motor. The 3D finite element electromagnetic model is adopted to calculate the UMP in the motorized spindle. The analysis results show that the eccentricity caused by thermal deformation can generate large UMP in the motorized spindle.

Key words: Unbalanced magnetic pull, synchronous motorized spindle, magneto-thermal coupling, air gap length, thermal deformation

\section{Introduction}

With the development of high-speed machining technology, a higher demand for the motorized spindle is required [1-3]. The motorized spindle with a built-in motor eliminates the mechanical transmission elements such as gears and couplings, which is well suitable for high-speed machining [4]. The magnetic field generated in the motor can interact with mechanical structures and thus produce unbalanced magnetic pull (UMP) [5]. If the air-gap distribution between the rotor and the stator is uniform, the electromagnetic forces cancel out each other and are balanced [6, 7]. Instead, if the rotor is eccentric with respect to the stator, the air-gap distribution is not uniform and causes UMP, which will lead to vibrations and noises in the motorized spindle shaft [8-10]. 
To investigate the effect of UMP on motorized spindle, the UMP must first be calculated accurately. In general, the studies on UMP can be roughly classified into two methods: analytical method and finite element method [11]. The analytical method is relatively simple and can thus be used for study of the influence of the UMP on stability of the rotor motion, but it cannot involve the effect of slot harmonics and saturation effect of a ferromagnetic core of rotor and stator windings [12]. By comparison, the finite element method can consider more parameters and provide more accurate and reliable solutions, but it requires more computational resources and long calculation time [11, 12]. Extensive research has been done on UMP due to air-gap eccentricity in recent years, including the static eccentricity [13], dynamic eccentricity [14], inclined eccentricity [15] and mixed eccentricity [16]. However, these studies on UMP are based on the assumption that both the rotor and stator are perfect cylinders. In engineering practice, the shape errors of the rotor are inevitable due to manufacturing deviation. Xu and Han [17] established a general electromagnetic model for the elliptical and corrugated shape deviations in PMSM supported by three-pole active magnetic bearings. In addition, curved dynamic eccentricity occurs to some extent when the shaft is bent under the effect of external forces. Di et al. [18] presented a new method to calculate the UMP in cage induction motors considering the curved dynamic eccentricity.

For motorized spindle, the thermal growth due to temperature raise becomes a critical issue to be considered with the increase of speed and power of motorized spindle [19]. The main heat sources in the motorized spindle are motor and bearings [20]. When the spindle unit is in rotational running state, the power loss of its motor and bearing friction heat cause temperature elevation and lead to thermal deformations of spindle parts [21]. Chen et al. [22] pointed out the air gap length can be altered by radial expansion of the spindle rotor. The experimental research of Chang et al. [23] also shows that the air gap length varies with the thermal deformation of the motorized spindle. Mover, Vaijone et al. [24] found that the variations of air gap length cause the change of stator copper losses and rotor eddy current losses. $\mathrm{Li}$ and $\mathrm{Wu}[25]$ drew a conclusion that the electromagnetic vibration of the motorized spindle increased with the rise of radial electromagnetic force when the air gap changes. The above researches all indicate that complex coupling relations exist between the air gap length and the thermal deformation of motorized spindle. However, up to now, the effect of magnetic-thermal coupling on UMP has not been well investigated.

This paper presents a two-way magneto-thermal coupling model, in which the mutual 
interaction between the electromagnetic parameters and temperature rise can be considered. The thermal deformations of the spindle are obtained and used to calculate UMP based on a 3D finite element electromagnetic model. Furthermore, the air gap length and UMP of motorized spindle due to thermal deformations are analyzed.

\section{Magneto-thermal coupling model}

\subsection{Parameters of motorized spindle}

The schematic of the motorized spindle investigated in this paper is illustrated in Fig.1. The shaft of the motorized is supported by two pairs of angular contact ball bearings. A built-in permanent magnet synchronous motor is adopted to drive the shaft to rotate. A water circuit cooling jacket is placed around the stator of the built-in motor. Oil-air lubrication is used for the bearings. The parameters of the motor and bearings are listed in Tab. 1 and Tab. 2 respectively.

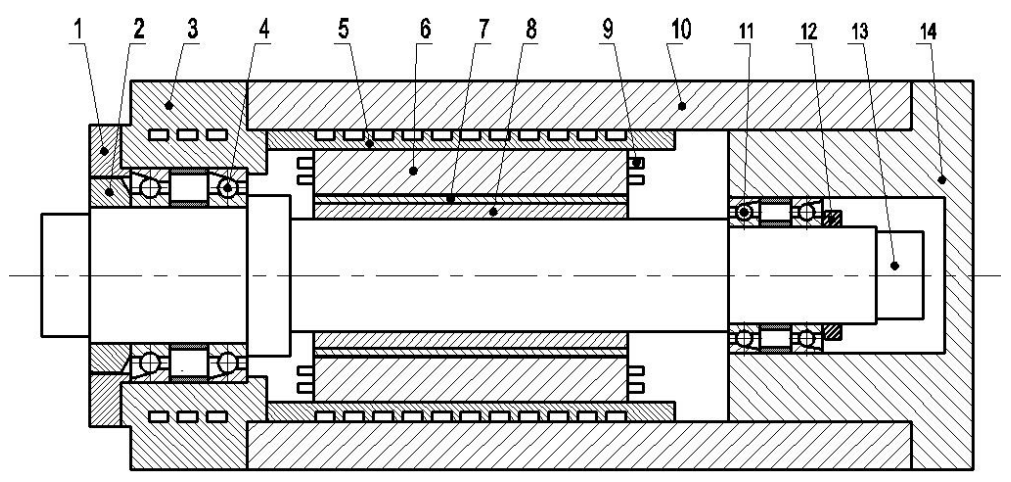

1.front end housing 2 .front locknut $\quad 3$. front bearing pedestal $\quad$ 4.front bearing 5.cooling water jacket 6.stator 7.permanent magnet 8.rotor 9.winding 10.spindle casing 11.rear bearing 12.rear locknut 13.shaft 14.rear bearing pedestal

Fig.1 Sketch of motorized spindle

Table 1 Structure parameters of built-in motor

\begin{tabular}{cccc}
\hline Parameter & Value & Parameter & Value \\
\hline Rated power & $45 \mathrm{KW}$ & Rotor outer diameter & $82.5 \mathrm{~mm}$ \\
Rated speed & $18000 \mathrm{rpm}$ & $\begin{array}{c}\text { Rotor/stator } \\
\text { length }\end{array}$ & axial \\
Rated torque & $24 \mathrm{~N} \cdot \mathrm{m}$ & Pole pair number & 3 \\
Rated current & $72 \mathrm{~A}$ & Stator slot number & 36 \\
Stator $\quad$ outer & $130 \mathrm{~mm}$ & Phase number & 3 \\
diameter & $83.5 \mathrm{~mm}$ & Air gap length & $0.5 \mathrm{~mm}$ \\
Stator inner diameter & &
\end{tabular}


Table 2 Structure parameters of bearings

\begin{tabular}{ccc} 
Parameter & Front bearing & Rear bearing \\
\hline Type & SKF & SKF \\
Inner diameter $(\mathrm{mm})$ & 7014ACE/HCP4ADTA & 7010ACE/HCP4ADTA \\
Outer diameter $(\mathrm{mm})$ & 70 & 50 \\
Ball number & 110 & 80 \\
Ball diameter $(\mathrm{mm})$ & 25 & 21 \\
Contact angle $\left({ }^{\circ}\right)$ & 9.525 & 21 \\
\hline
\end{tabular}

2.2 Thermal model of the motorized spindle

\subsubsection{FEM model}

The thermal model of the motorized spindle was established in ANSYS Workbench. To reduce the computational time, 1/6 model of the spindle is adopted considering its structural symmetry. For the same reason, some small structures such as thread hole, key groove, chamfer and fillet were also simplified due to their little effect on the analysis result [26]. Both hexagonal and tetrahedral element were used in the model. The region with higher temperature gradient such as motor and bearings was meshed much more refined. The meshed model is shown in Fig.2. The material properties of the spindle are listed in Tab.3.

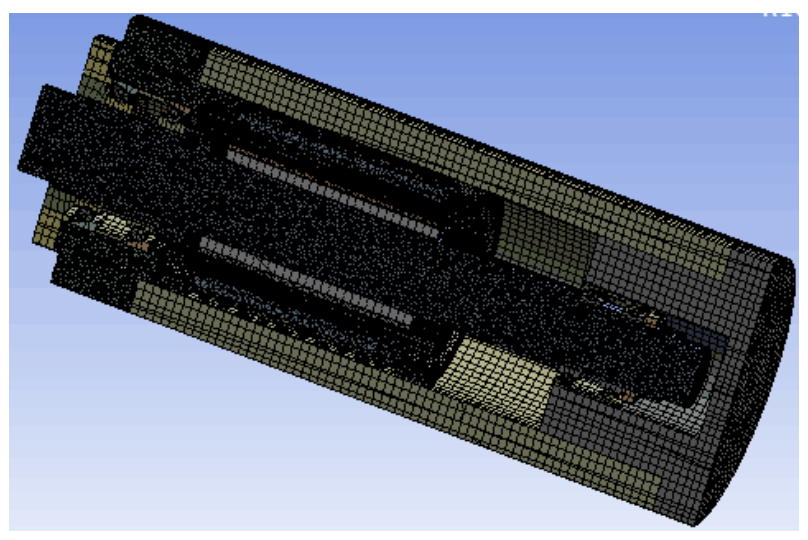

Fig.2 3D model of motorized spindle 
Table 3 Material parameters of motorized spindle

\begin{tabular}{lcccccc}
\hline Material & $\begin{array}{l}\text { Density } \\
\left(\mathrm{Kg} / \mathrm{m}^{3}\right)\end{array}$ & $\begin{array}{l}\text { Heat } \\
\text { conductivity } \\
\text { coefficient } \\
(\mathrm{W} /(\mathrm{m} . \mathrm{K}))\end{array}$ & $\begin{array}{l}\text { Specific } \\
\text { heat } \\
(\mathrm{J} / \mathrm{kg} / \mathrm{K})\end{array}$ & $\begin{array}{l}\text { Poisson's } \\
\text { ratio }\end{array}$ & $\begin{array}{l}\text { Young's } \\
\text { Modulus } \\
(\mathrm{GPa})\end{array}$ & $\begin{array}{l}\text { Linear } \\
\text { expansion } \\
\text { Coefficient } \\
\left(\mathrm{K}^{-1}\right)\end{array}$ \\
\hline $\begin{array}{l}\text { Spindle } \\
\text { casing } \\
(3 \mathrm{CR} 13)\end{array}$ & 7750 & 60 & 434 & 0.3 & $2.06 \times 10^{11}$ & $1.02 \times 10^{-5}$ \\
$\begin{array}{c}\text { Spindle } \\
(40 \mathrm{Cr})\end{array}$ & 7820 & 39.2 & 460 & 0.29 & $2.06 \times 10^{11}$ & $1.19 \times 10^{-5}$ \\
$\begin{array}{c}\text { Winding } \\
(\text { copper })\end{array}$ & 8933 & 385 & 390 & 0.33 & $1.1 \times 10^{11}$ & $1.89 \times 10^{-5}$ \\
$\begin{array}{c}\text { Permanent } \\
\text { magnet } \\
(\mathrm{NdFeB})\end{array}$ & 7500 & 9 & 504 & 0.24 & $1.6 \times 10^{11}$ & $4 \times 10^{-6}$ \\
$\begin{array}{c}\text { Stator/rotor } \\
\text { (stalloy) }\end{array}$ & 7650 & $\begin{array}{l}\mathrm{X}: 39 \\
\mathrm{Z}: 3.43\end{array}$ & 460 & 0.26 & $2 \times 10^{11}$ & $1.22 \times 10^{-5}$ \\
\hline
\end{tabular}

\subsubsection{Heat generation}

The heat generated in bearings can be obtained by the following equation [27]

$$
H_{f}=1.047 \times 10^{-4} n_{s} M
$$

where $n_{s}$ is the rotating speed of the spindle, $M$ is the total frictional torque of the bearing.

The total frictional torque $M$ is the sum of the load torque $M_{l}$ and viscous friction torque $M_{v}$

$$
M=M_{l}+M_{v}
$$

The load torque $\mathrm{M}_{l}$ can be approximated by the following equation

$$
M_{l}=f_{l} p_{l} D_{m}
$$

where $f_{l}$ is a factor related to the bearing type and load, $p_{l}$ depends on the magnitude and direction of the bearing load, and $D_{m}$ is the mean diameter of the bearing.

The viscous friction torque $M_{v}$ can be given by the following equation

$$
\begin{cases}M_{s}=160 \times 10^{-7} f_{v} D_{m}{ }^{3} & v_{0} n_{s}<2000 \\ M_{s}=10^{-7} f_{v}\left(v_{0} n_{s}\right)^{2 / 3} D_{m}{ }^{3} & v_{0} n_{s} \geq 2000\end{cases}
$$

where $f_{v}$ is a factor related to bearing type and lubrication method, $v_{0}$ is the kinematic viscosity of the lubricant.

The main power losses occurring in the permanent magnet synchronous motor are stator 
winding losses, stator and rotor core losses [28]. Although the rotor eddy current loss is relatively small compared with the stator copper and iron losses, it may cause significant heating of the permanent magnets and cannot be ignored [29].

The stator winding losses $P_{C u}$ can be expressed by

$$
P_{C u}=s I^{2} R K_{S}
$$

where $s$ is the number of phases, $I$ is the stator current, $R$ is stator winding resistance and $K_{\mathrm{s}}$ is the skin effect coefficient for stator conductors.

The losses of the stator and rotor core losses $P_{F e}$ can be calculated by [28]

$$
P_{F e}=\Delta p_{1 / 50}(f / 50)^{4 / 3} k_{a} B^{2} m_{c}
$$

where $k_{\mathrm{a}}$ is the factor taking the increase in losses due to metallurgical and manufacturing processes into account, $B$ is the magnetic flux density, $m_{c}$ is the mass of the core and $\triangle p_{1 / 50}$ is the specific core loss at $B=1 \mathrm{~T}$ and $f=50 \mathrm{~Hz}$.

The eddy current loss density distribution $W_{e}$ can be obtained from [29]

$$
W_{e}=\pi^{2} f \gamma h_{m}^{2} \cdot \sum_{n=1}^{\infty} \frac{n^{2}\left(a_{n}^{2}+b_{n}^{2}\right)}{2}
$$

where $\gamma$ is the electrical conductivity of the permanent magnet, $h_{m}$ is the thickness of the $\mathrm{NdFeB}$ material, $a_{n}$ and $b_{n}$ are the harmonic amplitude of the magnetic flux density due to the effect of the armature reaction field, and $n$ is the harmonic order.

\subsubsection{Convection boundary condition}

The coefficient of convection heat transfer $h_{c}$ can be computed by the following equation

$$
h_{c}=\frac{N_{u} \lambda}{D_{h}}
$$

where $N_{u}$ is the Nusselt number, $\lambda$ is the thermal conductivity of the fluid, and $D_{h}$ is the hydraulic diameter. A free convection can be assumed for ambient air around a stationary surface like the spindle housing and $\lambda$ can be obtained as $9.7 \mathrm{~W} /\left(\mathrm{m}^{2} \mathrm{~K}\right)$.

The $N_{u}$ is determined based on different heat convection conditions [30]. For calculating $N_{u}$, the following equations are used [31, 32]

$$
N_{u}=0.133 \operatorname{Re}^{2 / 3} \operatorname{Pr}^{1 / 3}\left(\operatorname{Re}<4.3 \times 10^{5}, 0.7<\operatorname{Pr}<670\right)
$$


where

$$
\begin{gathered}
\operatorname{Re}=\frac{u_{\text {fluid }} D_{h}}{v_{\text {fluid }}} \\
\operatorname{Pr}=\frac{c_{\text {fluid }} \mu_{\text {fluid }}}{k_{\text {fluid }}}
\end{gathered}
$$

Where $u_{f l u i d}$ is the velocity, $v_{\text {fluid }}$ is the kinematic viscosity, $c_{f f u i d}$ is the specific heat capacitance and $k_{\text {fluid }}$ is the dynamic viscosity of the air. Under normal temperature, $v_{\text {fluid }}$ equals to $16 \mathrm{~mm}^{2} / \mathrm{s}, \operatorname{Pr}$ equals to 0.701 .

2.3 Electromagnetic field model of the motorized spindle

With the increase of temperature in the built-in motor, the resistance of the winding and the permanent magnet will change correspondingly, and the winding loss and the eddy current loss of the permanent magnet will change. In this paper, the influence of temperature rise on the material property of the motor was considered. The electromagnetic field model of the motor is established based on FEM in Ansoft Maxwell software, as shown in Fig.3. The model here is mainly to solve the electromagnetic loss of the built-in motor, and the accuracy requirement is not too high, therefore the adaptive mesh was adopted to save computation time. The detailed parameters of the motor are listed in Tab.2.

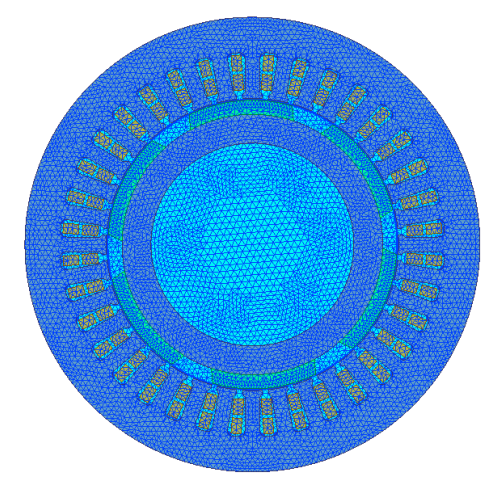

Fig.3 Magnetic field model of motorized spindle

2.4 Magneto-thermal coupling analysis

A two way magneto-thermal coupling analysis was conducted based on the above models. In the coupling analysis, the electromagnetic losses obtained from the electromagnetic field model are imported into the temperature field model to calculate the temperature distribution, and the electromagnetic material property parameters are changed according to the temperature rise and the 
electromagnetic losses are then updated accordingly. The coupling iteration is repeated until the temperature value of two consecutive iteration steps show minor deviation, which is set as $0.1^{\circ} \mathrm{C}$ in this paper. In this way, the data of electromagnetic field and temperature field can be two-way transmitted. The scheme of the two-way coupling process is shown in Fig.4

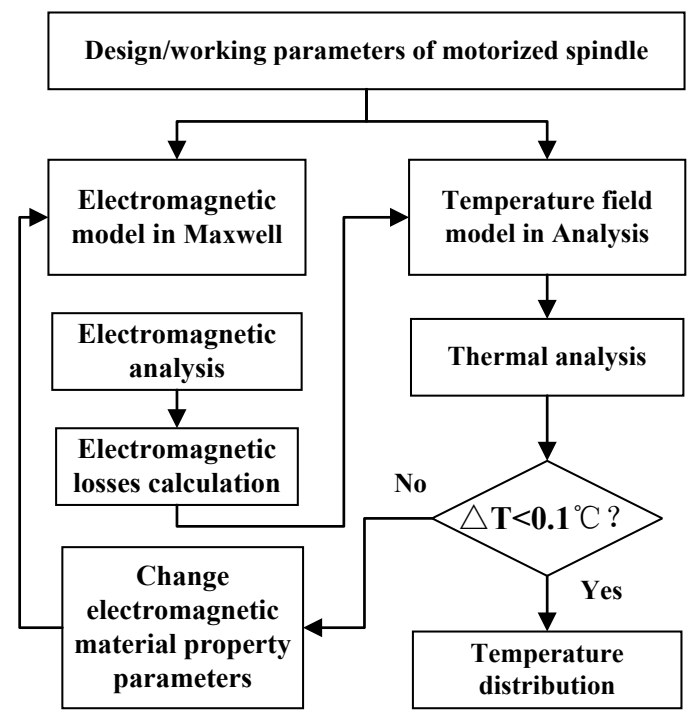

Fig.4 Scheme of two way magneto-thermal coupling analysis

When the rotating speed of the spindle is $2,000 \mathrm{rpm}$ and the ambient temperature is $18^{\circ} \mathrm{C}$, the temperature field distributions of the motor are shown in Fig.5. Experiments were conducted on a motorized spindle test rig to verify the simulation method, as is depicted in Fig.6. The experimental motorized spindle is the corresponding physical entity of the model in Fig.1. To measure the temperature, a PT100 sensor was embedded in the motor. Since it is difficult to install sensors on the rotor, only the temperatures of the end winding of the motor were measured and used for comparison. As can be seen in Fig. 7, the simulated temperature values at a given time of 2400s are in good agreement with the experimental results.

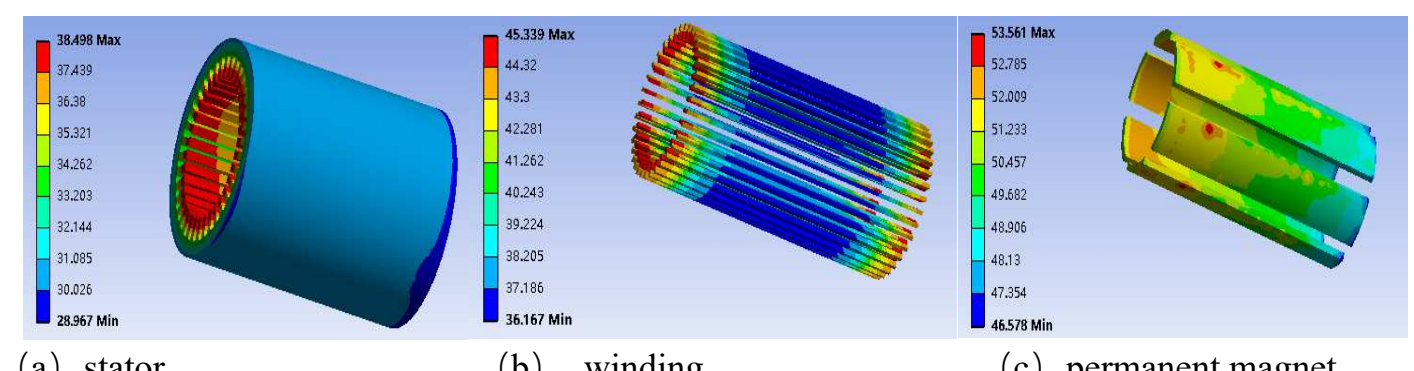
(a) stator
(b) winding
(c) permanent magnet

Fig.5 Temperature field distributions of motor 


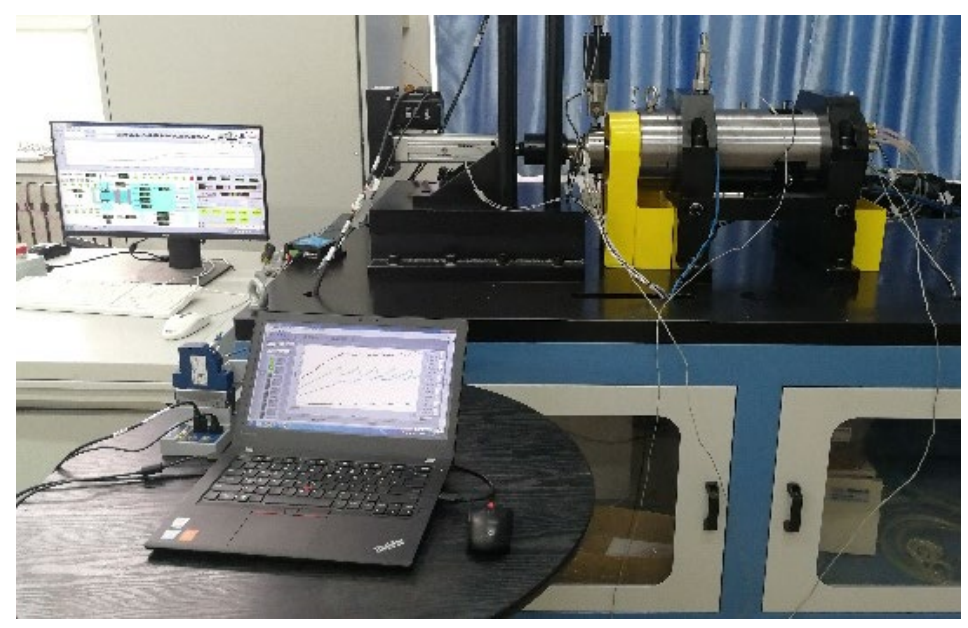

Fig.6 Motorized spindle test rig

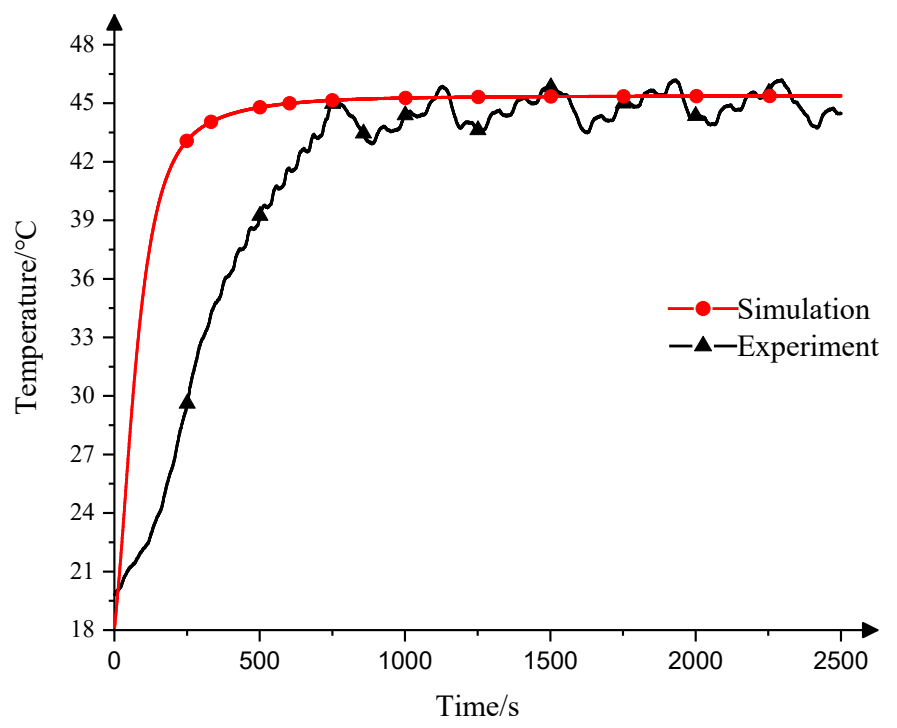

Fig.7 Comparisons of simulated temperatures and experiment results

\section{Thermal deformation of the motor}

The thermal-structure coupling analysis was performed in Ansys Workbench to obtain the thermal deformation of the motor. In order to analyze the change of air gap length, the thermal deformations of the rotor and the stator are required. The stator inner surface and the permanent magnet outer surface are each divided into 15 layers along the Z-axis direction from one side of the shaft to the other side as showed in Fig. 8(a). The figure also illustrates the deformations of the permanent magnet that occur due to the temperature rise of the motor. In Fig. 8(b), 30 uniformly distributed nodes of each layer are selected, and their corresponding deformations are obtained from the thermal-structure coupling model. The multilayer 3D model is shown in Fig. 8(c) and Fig. 8(d). 


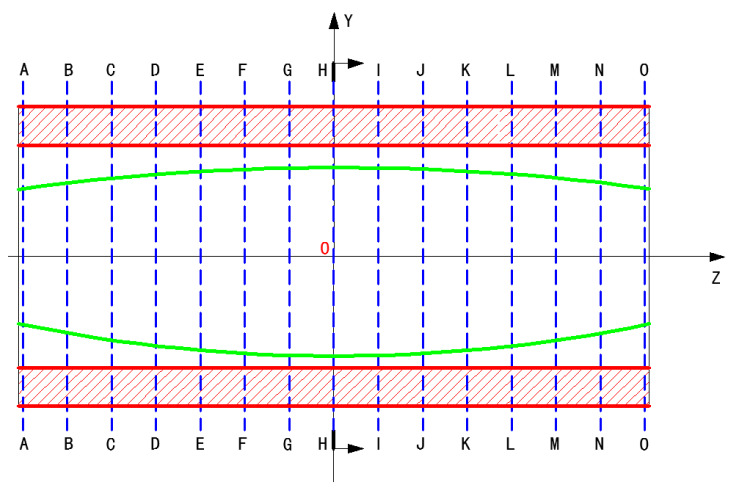

(a)

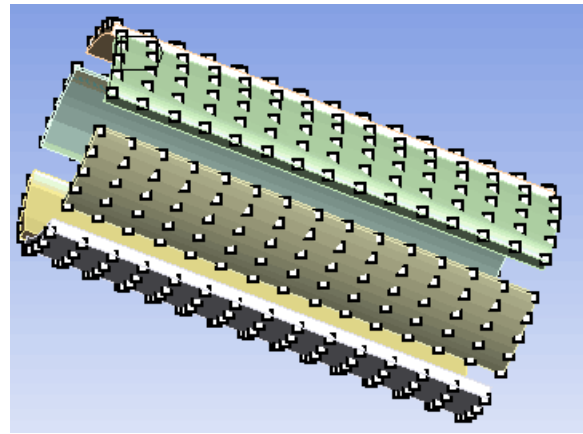

(c)

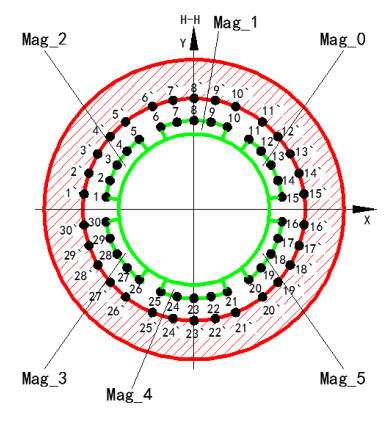

(b)

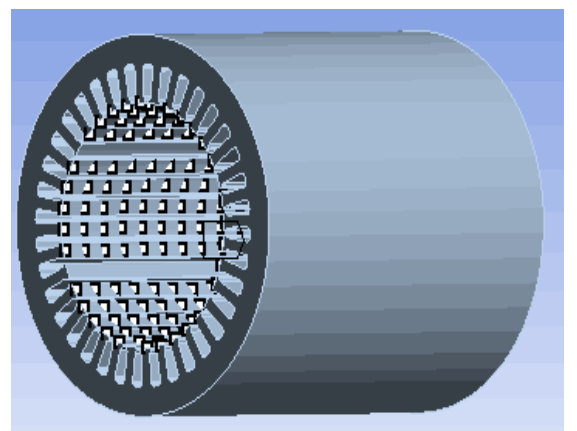

(d)

Fig.8 Selected nodes for thermal deformation calculation. (a) Layering diagram along the Zaxis. (b) Nodes in each layer. (c) Marked nodes in permanent magnet 3D model. (d) Marked nodes in stator 3D model.

Fig. 9 shows the deformations in $\mathrm{X}$ direction of the permanent magnet and the stator. The maximum thermal deformation of the stator is $10.168 \mu \mathrm{m}$ and the counterpart of the permanent magnet is $16.234 \mu \mathrm{m}$. The deformations of node 16 in each layer of permanent magnet and node 16' in each layer of the stator along the Z-axis are shown in Fig.10. It can be seen that the deformations of the stator inner surface are small in the middle and large on both sides, while the deformations of rotor permanent magnets are large on the left and small on the right. Thus, the air gap length has a tendency to decrease.

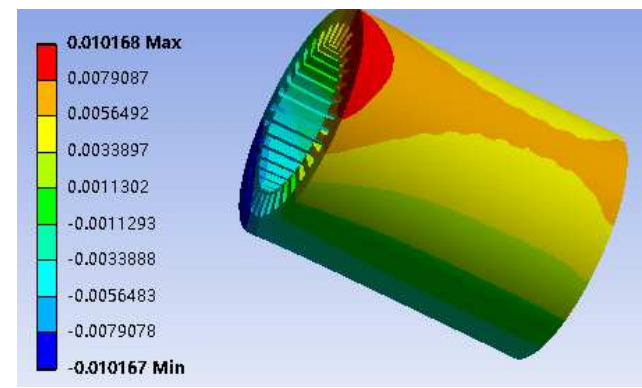

(a)

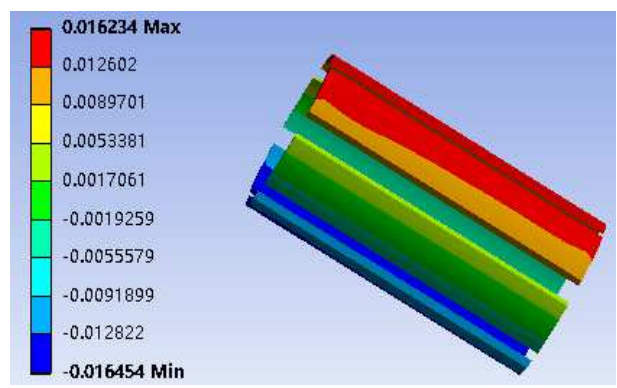

(b)

Fig.9 Thermal deformations in $\mathrm{x}$ direction. (a)Deformation nephogram of stator. (b)

Deformation nephogram of permanent magnet. 


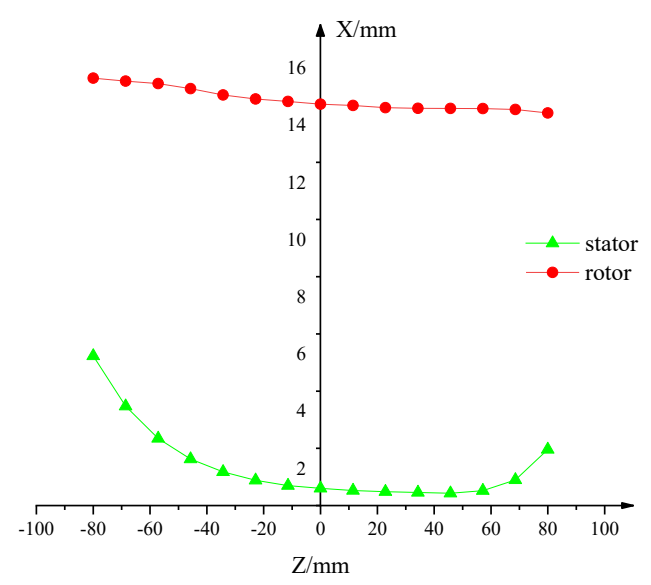

Fig.10 The deformations in $\mathrm{x}$ direction of the stator and permanent magnet along the $\mathrm{Z}$-axis

Fig. 11 shows the deformations in $\mathrm{Y}$ direction of the permanent magnet and the stator. The maximum thermal deformation of the stator is $32.442 \mu \mathrm{m}$ and the counterpart of the permanent magnet is $41.731 \mu \mathrm{m}$. The deformations of node 8 in each layer of permanent magnet and node $8^{\prime}$ in each layer of the stator along the Z-axis are shown in Fig.12. It can be seen that the deformations of the stator inner surface are small in the middle and large on both sides, while the deformations of the rotor permanent magnet are small on the left and large on the right. Thus, the air gap length has a tendency to decrease.

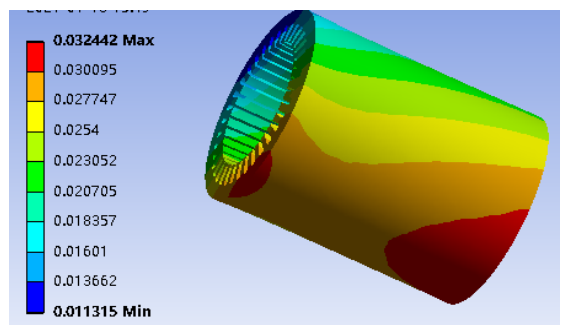

(a)

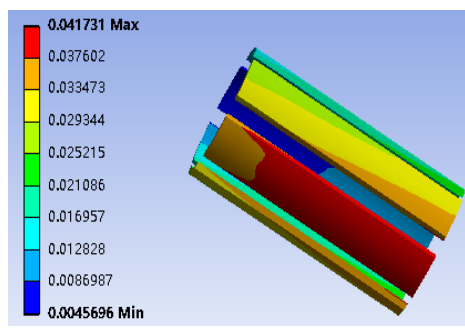

(b)

Fig.11 Thermal deformations in $\mathrm{Z}$ direction. (a)Deformation nephogram of stator. (b) Deformation nephogram of permanent magnet.

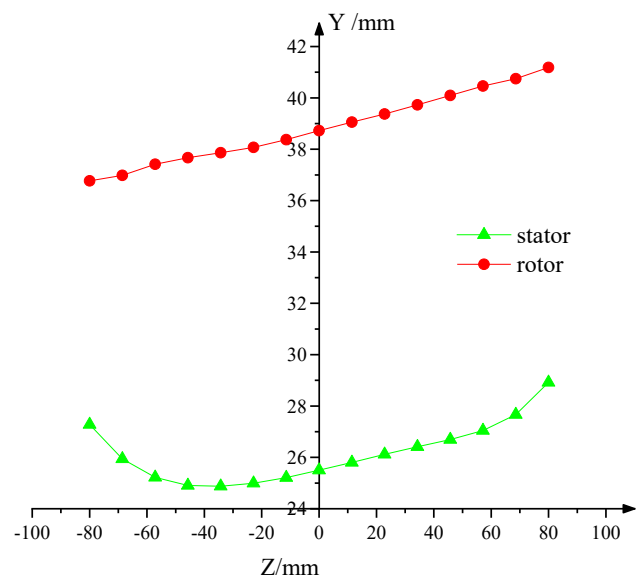

Fig.12 The deformations in $\mathrm{Y}$ direction of the stator and permanent magnet along $\mathrm{Z}$ axis 


\section{Air gap length of the motor}

The air gap length of the motor can be calculated when the thermal deformations of the stator and permanent magnet are obtained. To analyze the air gap length due to thermal deformation, the locations 8-8', 23-23', 16-16' and 30-30' of the motor are selected. The air gap lengths of 16-16' and 30-30' of the motor along the Z-axis are illustrated in Fig.13. It can be seen that the air gap length at both locations are smaller than the original air gap length of $0.5 \mathrm{~mm}$. The air gap lengths of 30-30' are larger than those of 16-16', which indicates the rotor occurs an offset with respect to the stator in positive $\mathrm{X}$ direction. The air gap lengths of $8-8^{\prime}$ and $23-23^{\prime}$ of the motor along the Zaxis are illustrated in Fig.14. It can be seen that the air gap length at both locations are smaller than the original air gap length of $0.5 \mathrm{~mm}$. The air gap lengths of 8-8' are larger than those of 23-23', which indicates the rotor is bent toward the stator in negative $\mathrm{Y}$ direction.

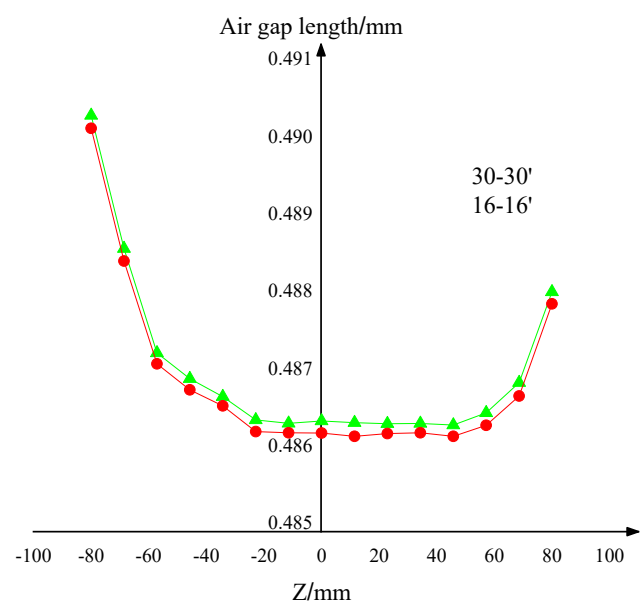

Fig.13 The air gap length of 16-16' and 30-30' along the Z-axis

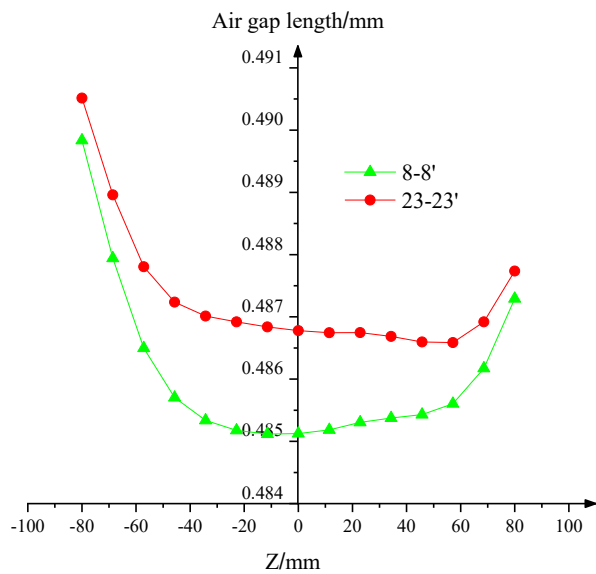

Fig.14 The air gap length of 8-8' and 23-23' along the Z-axis 


\section{UMP of the motor}

As previously analyzed, the thermal deformations of the motor occurs in the 3D space. In order to represent the deformations of different layers in the motor, a 3D finite element electromagnetic model is needed to calculate the UMP. The finite element model of the motor in Ansoft Maxwell is shown in Fig.15. Since the electromagnetic forces act on rotor through the permanent magnet, the forces of the permanent magnet are analyzed as shown in Fig.16. It can be seen that the forces of Mag_4 and Mag_5 are apparently larger than those of Mag_1 and Mag_2. The reason is that the permanent magnets occur offset and bending due to thermal deformations which causes the changes of air gap length. When the air-gap distribution between the rotor permanent magnet and the stator is not uniform, the electromagnetic forces cannot cancel out each other and are thus unbalanced.

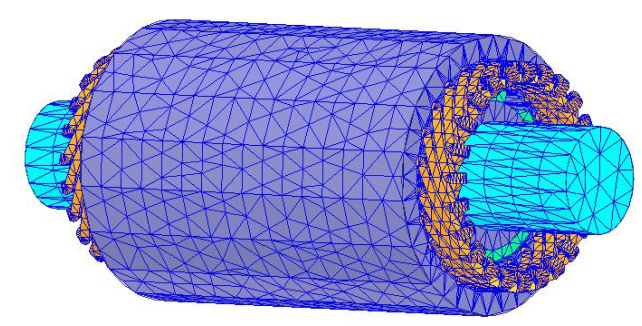

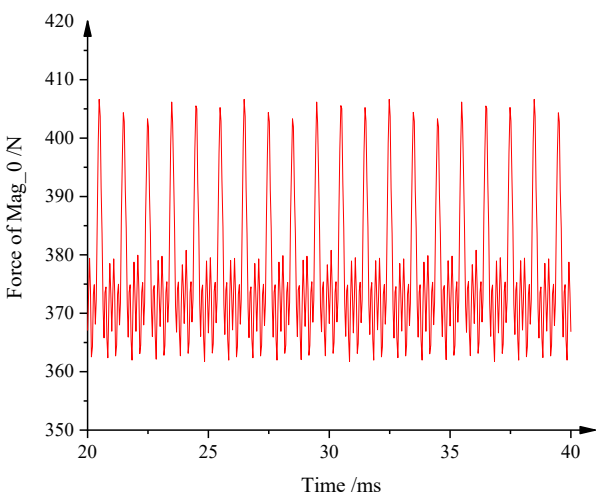

(a)

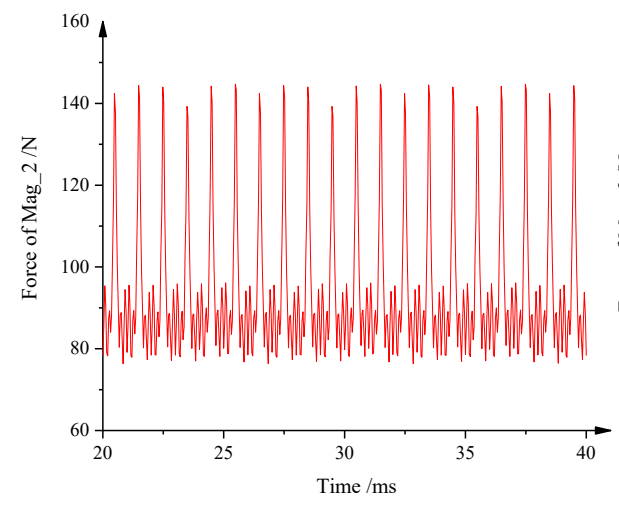

(c)

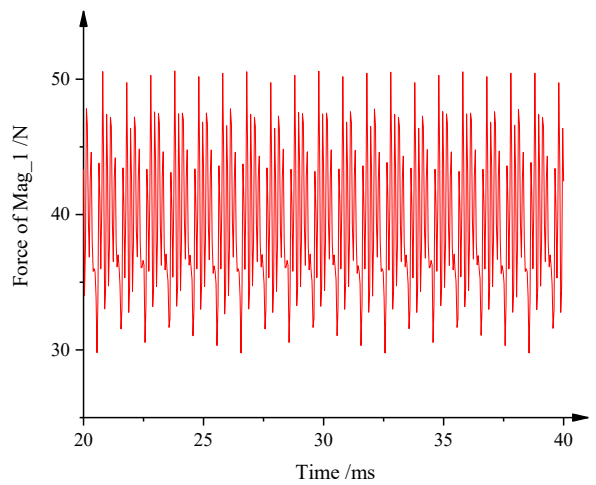

(b)

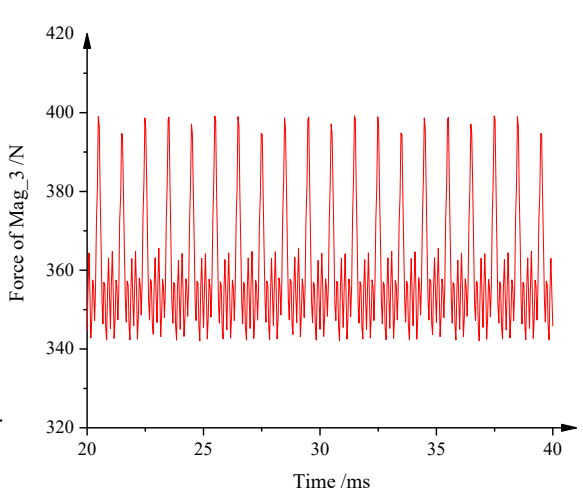

(d) 


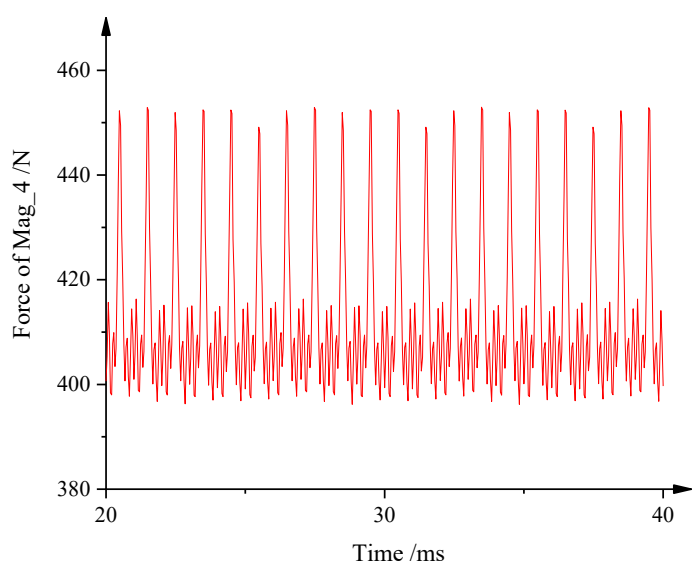

(e)

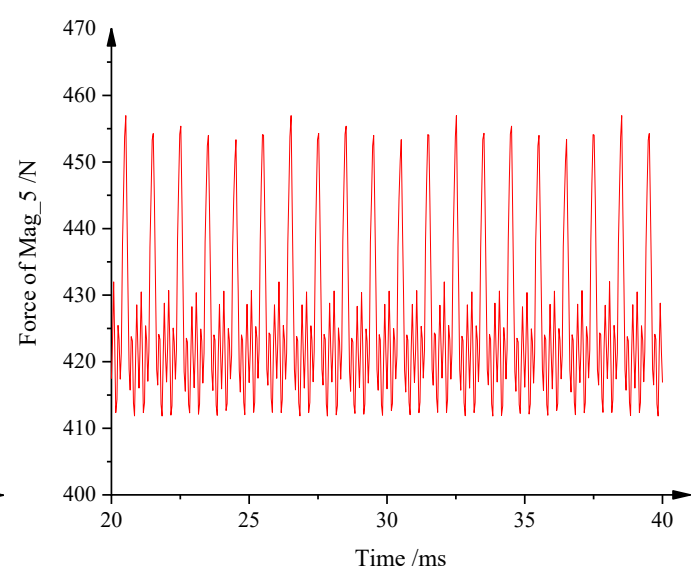

(f)

Fig.16 The electromagnetic forces acting on rotor permanent magnets. (a) Permanent magnet Mag_0. (b) Permanent magnet Mag_1. (c) Permanent magnet Mag_2. (d) Permanent magnet Mag_3. (e) Permanent magnet Mag_4. (f) Permanent magnet Mag_5.

In order to investigate the changes of the electromagnetic forces with time, the forces of permanent magnet Mag_3 in X, Y and Z directions are selected and shown in Fig.17. It can be seen that the forces in $\mathrm{X}$ and $\mathrm{Y}$ direction vary basically in sinusoidal waveform, and they are symmetric with respect to the zero coordinate. The reason is that dynamic eccentricity occurs in permanent magnet Mag_3 and the change in its air gap length is relatively small. Thus, the electromagnetic forces of permanent magnet Mag_3 are mainly related to the magnetic field generated by the threephase sinusoidal alternating current in the stator winding. The air gap length of Mag_3 is uneven and can thus lead to unbalanced electromagnetic pull. It is noted that the variation pattern of the forces of other permanent magnets are similar to those of permanent magnet Mag 3.

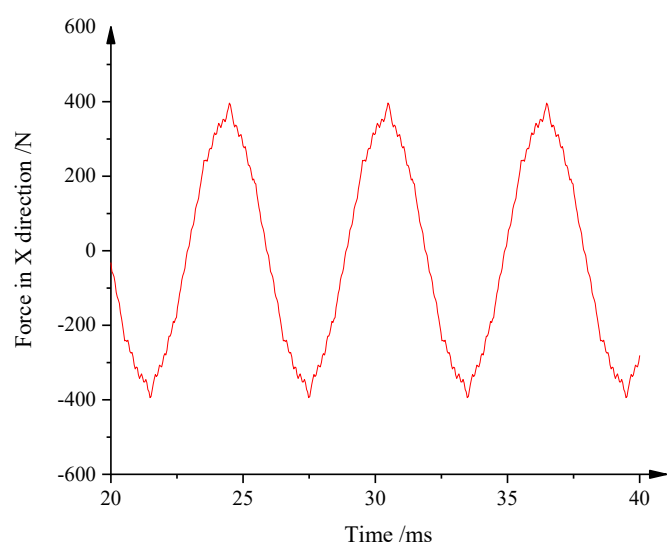

(a)

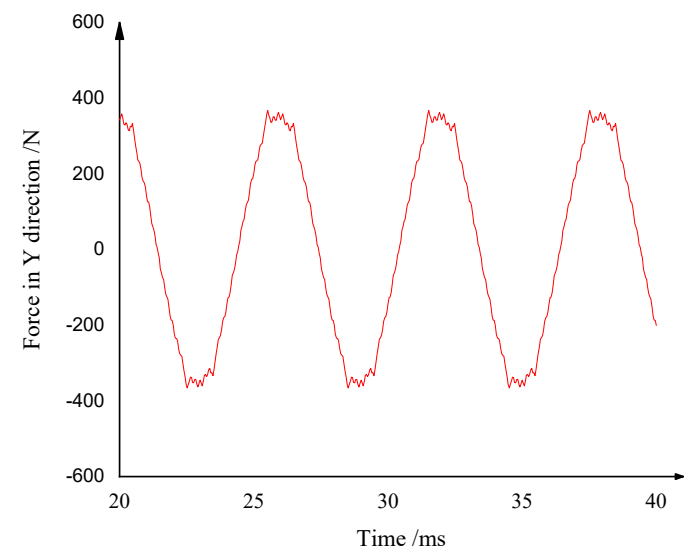

(b) 


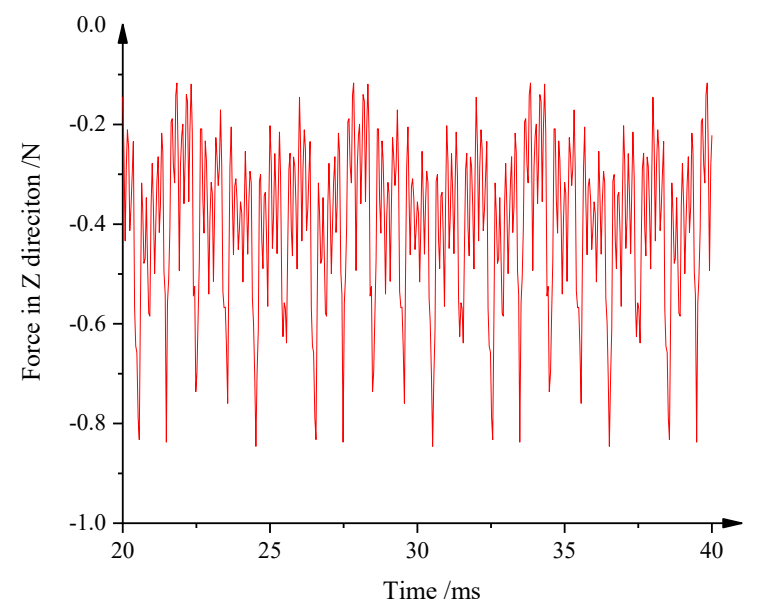

(c)

Fig.17 The electromagnetic forces of permanent magnet Mag_3. (a) Forces in X axis direction. (b) Forces in $\mathrm{X}$ axis direction. (c) Forces in $\mathrm{Z}$ axis direction.

Fig.18 shows the changes in total electromagnetic forces of all the permanent magnets with time in initial state and thermal steady state respectively. It can be seen the total electromagnetic forces in thermal steady state are much larger than those in initial state. Therefore, it can be inferred that there is a strong correlation between the thermal deformation and the UMP. Nevertheless, the air gap length and then the UMP may show various patterns due to complexity of the thermal deformations in space.
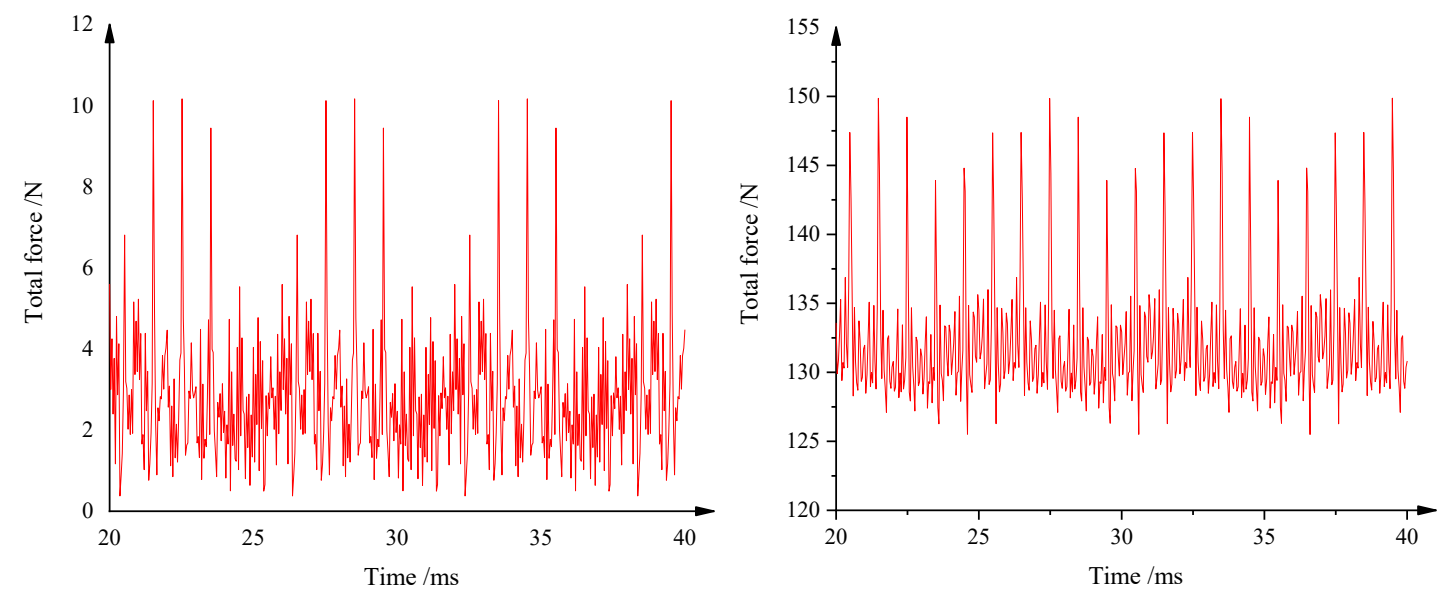

Fig.18 The total electromagnetic forces of permanent magnets. (a) Forces in initial state.

(b) Forces in thermal steady state.

\section{Conclusion}

This paper proposes a calculation model of UMP in a synchronous motorized spindle considering the magneto-thermal coupling effect. The temperature field distribution, the thermal 
deformations, and the air gap length of the motorized spindle are obtained. It is found that the spindle generates thermal deformations that occur in three-dimensional space, which will cause uneven air gaps between the rotor and stator. The analysis results also reveal that complex coupling relations exist between the air gap length and the thermal deformation of the motorized spindle. Therefore, the thermal deformations must be considered in the calculation of UMP. The proposed method in this paper will be helpful for the further investigation of vibration in motorized spindle with curved dynamic eccentricity.

\section{Acknowledgement}

This work was supported by the National Natural Science Foundation of China (12072106, 52005156 and 51805148), the Fundamental Research Funds for the Henan Provincial Colleges and Universities in Henan University of Technology (2018QNJH04), the Key Scientific Research Program of Henan Provincial colleges and universities (20A460007), the Key Scientific and Technological Project of Henan Province (202102210288 and 212102210618), and the National Key Research and Development Program of China (2020YFB2008101).

\section{Declarations}

\section{-Ethical Approval}

Not applicable

\section{-Consent to Participate}

Not applicable

-Consent to Publish

-Authors Contributions

Feng W: Conceptualization, Methodology, Writing-original draft. Zhang K: Investigation, Validation, Formal analysis. Liu Z: Conceptualization, Software. Liu B: Editing, Validation. Zhang

H: Visualization, Investigation. Mei J: Experiment. Wu L: Writing - review.

\section{-Funding}

-Competing Interests 
Not applicable

-Availability of data and materials

Not applicable

\section{Reference}

[1] Liu J , Chen X . Dynamic design for motorized spindles based on an integrated model. Int. J. Adv. Manuf. Technol., 71,961-1974(2014).

[2] Yang J , Shi H , Feng B , et al. Thermal error modeling and compensation for a high-speed motorized spindle. Int. J. Adv. Manuf. Technol., 77,1005-1017(2015).

[3] Feng W, Liu B, Yao B, et al. An integrated prediction model for the dynamics of machine tool spindles. Mach. Sci. Technol., 22(6), 968-988(2018).

[4] Abele E , Altintas Y, Brecher C . Machine tool spindle units. CIRP Annals - Manufacturing Technology, 59(2),781-802(2010).

[5] Im H , Hong H Y, Chung J . Dynamic analysis of a BLDC motor with mechanical and electromagnetic interaction due to air gap variation. J. Sound Vib., 330,1680-1691(2011).

[6] Pennacchi P. Computational model for calculating the dynamical behavior of generators caused by unbalanced magnetic pull and experimental validation. J. Sound Vib. 312,332-353(2008).

[7] Xiang C , Liu F, Liu H , et al. Nonlinear dynamic behaviors of permanent magnet synchronous motors in electric vehicles caused by unbalanced magnetic pull. J. Sound Vib., 371,277-294(2016).

[8] Wu Q, Y Sun, Chen W, et al. Theoretical prediction and experimental verification of the unbalanced magnetic force in air bearing motor spindles. P. I. Mech. Eng. B-J. Eng. Manuf, 233(3),095440541983865(2019).

[9] Wang J, Jing M, Fan H, et al. Study on unbalance magnetic pull of the motorized spindle under different rotor eccentricities. In: International conference on ubiquitous robots and ambient intelligence, Xi'an, China, 19-22 August 2016, 781-785. New York: IEEE.

[10] Feng W , Zhang K , Liu B , et al. Dynamic modeling and vibration response analysis of a synchronous motorized spindle with inclined eccentricity, J. Vib. Control, 0,1-15(2021).

[11] Xu X, Han Q and Chu F. Review of electromagnetic vibration in electrical machines. Energies, 11,1779(2018). 
[12] Donát, Martin. Computational Modelling of the Unbalanced Magnetic Pull by Finite Element Method. Procedia Engineering, 48,83-89(2012).

[13] Liu F, Xiang C, Liu H, et al. Asymmetric effect of static radial eccentricity on the vibration characteristics of the rotor system of permanent magnet synchronous motors in electric vehicles. Nonlinear Dyn., 96,2581-2600(2019).

[14] Babaei M , Faiz J , Ebrahimi B M, et al. A Detailed Analytical Model of a Salient-Pole Synchronous Generator Under Dynamic Eccentricity Fault. IEEE Trans. Magn., 47(4),764771(2011).

[15] Xu X, Han Q , Chu F . A four degrees-of-freedom model for a misaligned electrical rotor. $J$. Sound Vib., 358,356-374(2015).

[16] Ebrahimi B M , Akin B , et al. Finite-Element Transient Analysis of Induction Motors Under Mixed Eccentricity Fault. IEEE Trans. Magn., 44(1),66-74(2007).

[17] Xu X , Han Q . A general electromagnetic model and vibration control for shape deviations in PMSM supported by three-pole active magnetic bearings. Mech. Syst. Sig. Process., 158,107710(2021).

[18] Di C , Bao X, Wang H, et al. Modeling and Analysis of Unbalanced Magnetic Pull in Cage Induction Motors With Curved Dynamic Eccentricity. IEEE Trans. Magn., 51,1-7(2015).

[19] Hsieh K H , Chen T R , Chang P, et al. Thermal growth measurement and compensation for integrated spindles. Int. J. Adv. Manuf. Technol., 64,889-901(2013).

[20] Bossmanns B , Tu J F . A Power Flow Model for High Speed Motorized Spindles-Heat Generation Characterization. J. Manuf. Sci. Eng., 123,3(2001).

[21] Teng L, Gao W, Zhang D , et al. Analytical modeling for thermal errors of motorized spindle unit. Int. J. Mach. Tools Manuf, 112,53-70(2017).

[22] Chen J S , Hsu W Y . Characterizations and models for the thermal growth of a motorized high speed spindle. Int. J. Mach. Tools Manuf, 43(11),1163-1170(2003).

[23] CF Chang, Chen J J. Vibration monitoring of motorized spindles using spectral analysis techniques. Mechatronics, 19(5):726-734(2009).

[24] Valtonen M, Parviainen A, Pyrhonen J . Influence of the air-gap length to the performance of an axial-flux induction motor 2008 18th International Conference on Electrical Machines. IEEE, 2009. 
[25] Li T, Jian W . Electromagnetic Vibration Analysis of High Speed Motorized Spindle Considering Length Reduction of Air Gap. Int. J. Comput. Electr. Eng., 19(5),456-464(2017).

[26] Ma C , Yang J , Zhao L, et al. Simulation and experimental study on the thermally induced deformations of high-speed spindle system. Appl. Therm. Eng., 86,251-268(2015).

[27] Zhao H , Yang J , Shen J . Simulation of thermal behavior of a CNC machine tool spindle. Int. J. Mach. Tools Manuf, 47(6),1003-1010(2007).

[28] Uhlmann E , Hu J . Thermal Modelling of a High Speed Motor Spindle. Procedia CIRP, 1(1),313-318(2012).

[29] Wang X, Li J , Song P. The calculation of eddy current losses density distribution in the permanent magnet of PMSM Microwave Conference Proceedings, 2005. APMC 2005. Asia-Pacific Conference Proceedings. IEEE, 2006.

[30] Staton D A , Cavagnino A . Convection Heat Transfer and Flow Calculations Suitable for Electric Machines Thermal Models. IEEE Trans. Ind. Electron., 55(10),3509-3516(2008).

[31] Xu, Min, and, et al. An improved thermal model for machine tool bearings. Int. J. Mach. Tools Manuf, 47(1),53-62(2007).

[32] Teng L, Gao W, Zhang D , et al. Analytical modeling for thermal errors of motorized spindle unit. Int. J. Mach. Tools Manuf, 112,53-70(2017). 